\title{
Optimized synergy in FTTH infrastructure deployment: pragmatic as well as structural approaches
}

\author{
Sofie Verbrugge, Marlies Van der Wee, Jan Van Ooteghem, Jonathan Spruytte, Koen Casier \\ Dep. of Information Technology, Ghent University - iMinds, Gaston Crommenlaan 8, B-9050 Gent, Belgium \\ Tel: (32) 9 14880, Fax: (32) 9 14899, e-mail: sofie.verbrugge@intec.ugent.be
}

\begin{abstract}
Underground installation of utility infrastructures such as energy and telecoms is prevalent in large parts of Europe. As this labor-intensive trenching comprises 70-80\% of deployment cost, the overall investment for Fiber-to-theHome installations can be significant. Important reductions in these costs are possible by performing road works in synergy. With the increased level of detail in the geographical information bases containing all information on the installation per operator, opportunities for synergies are easier to spot and could lead to very important reductions in the operators' costs.

Policy measures recently also give a lot of focus in facilitating the rollout of high-speed broadband networks and cross-utility coordination. Several approaches can be considered to really capture potential savings and benefits in the deployment phase. This paper discusses pragmatic as well as structural approaches towards deployment cost optimization based on synergetic rollout schemes.
\end{abstract}

Keywords: FTTH rollout, infrastructure synergy, infrastructure deployment, synergy optimization

\section{THE NEED FOR FTTH DEPLOYMENT}

Broadband internet has in time become an essential infrastructure. Important economic as well as social benefits can be related to broadband deployments in general and Fiber-to-the-Home (FTTH) deployments in particular [1][2][3][4]. Therefore some countries or regions also set dedicated targets for broadband coverage and uptake. The most well-known example can be found in Europe's Digital Agenda (30Mbps to all by 2020), while the FCC in the US now follows with a minimum download speed of 25Mbps. In large parts of urban Europe, underground infrastructures are prevalent for conveying gas, water, electricity or telecom signals. Installation and maintenance of these underground infrastructures is very expensive partly due to the digging of the trench.

Several propositions to stimulate the rollout of broadband networks have been made. In Sweden, municipal fiber networks have been rolled out by the local governments and opened for competition on the network and service layer. This way, the investment cost for service providers is sharply decreased, since the network rollout investment is borne by the local government. Other measures to decrease the initial rollout cost is allowing aerial deployment of fiber cables, kick-start the deployment by connecting public buildings in a first phase or enforcing cooperation between utility networks. The latter approach forms the focus of the current paper.

After shortly sketching the legal framework and describing some known synergetic deployments, this paper will summarize our previous findings on a variety of potential approaches towards synergetic FTTH roll-out, highlighting potential roles for utility providers and government actors.

\section{LEGAL FRAMEWORK AND KNOWN SYNERGETIC DEPLOYMENTS}

With respect to FTTH infrastructure deployment, there is a plethora of regulatory obligations and guidelines, specified on European and national level (significant differences across countries can be found). One of the more important points refers to recommendations and obligations for infrastructure sharing.

The 2014/61/EU (2014, May) directive [5] specifies some minimum rights and obligations applicable across the Union in order to facilitate the rollout of high-speed electronic communications networks and cross-sector coordination. It basically discusses four efficiencies in the cost of civil engineering. First, the use of existing passive infrastructures (including those of other utilities) should be allowed in all cases, except when objective reasons can be put forward (like lack of availability or technical suitability or problems for public health, safety or network security). These infrastructures include gas, electricity (including public lighting), heating and water (including waste water and sewerage or drainage) as well as transport (railway, roads, ports and airports). The offer for access (including its price) should be fair and reasonable, which can be judged by a national dispute settlement body. Access to minimum information on available physical infrastructure (location and route, type, current use and contact point) will be provided via single information point, which should be publicly available from 2017 or should be available from any network provider upon request (within two months). Second, coordination of civil works should be available to and from every network operator. Therefore, every network operator should provide minimum information about their ongoing and planned works. Third, the burdensome administrative permit granting procedures should be handled within four months. All necessary information should 
be available through the single information point. Finally, all new buildings must be equipped with high-speed ready in-building infrastructure or at least with micro-ducts. Recently, also the FCC (2015, Feb.) pointed out to give fair access to poles and conduits to broadband providers, under Title II enforcement in the US.

Several synergetic rollouts can be observed in recent FTTH deployments. The Reykjavik fiber network is a subsidiary of Reykjavik Energy, an energy and utility company owned by the City of Reykjavik, Altibox in Norway was founded by Lyse Energi. Several FTTH network are initiated by the Stadtwerke in Germany e.g. Ruhrnet. M-Net Munchen has a strong cooperation with different utilities like Stadtwerke Munchen, Energie Wasser Verkehr, etc. In Denmark Waoo! networks are owned by different utility companies, without any public subsidy. At SwissCom in Switzerland there is a cooperation model between up to 4 partners (multiple fibers to the optical socket), supported by a PPP between Swisscom and utility firms splitting the investment risk.

\section{TRENCHING SYNERGIES AMONGST DIFFERENT UTILITY PROVIDERS}

When deploying a fiber access network by using a joint trench for multiple utility infrastructures, significant savings can be realized. In [6] an integrated model was built to define an optimal trench layout (Figure 1) and to estimate the impact of cooperation in the deployment phase on the rollout cost.

First, the model calculates an optimal trench for the set of infrastructures based on the legal safety constraints per infrastructure (minimal depth, distance to the wall of the trench and distance to other infrastructures) for any location in the network topology. In this optimization various different objectives (e.g. minimal time, minimal nuisance, etc.) could be pursued at the same time; the final solution will be a trade-off between the different alternative solutions found. Secondly, based on this optimal trench, the model allocates the different costs to the different actors (utility network owners) involved. Note that a scenario in which one actor is paying more in the cooperative case than he would be when executing the project alone, will not be executed in a cooperative setting. It is therefore crucial to find an appropriate allocation key in order to arrive at positive results for joint rollout for all utility firms involved.

In a use case for Belgium, considering both a greenfield and a brownfield scenario, the cooperative and independent rollout were compared, cost savings between 5 and 21\% [6] have been found in the deployment phase, depending on the pavement type and the number of utility infrastructure providers cooperating. These results indicate that recent policy measures towards duct sharing can have a significant positive impact on the rollout cost for the utility firms, while also benefiting the inhabitants through a reduced nuisance.
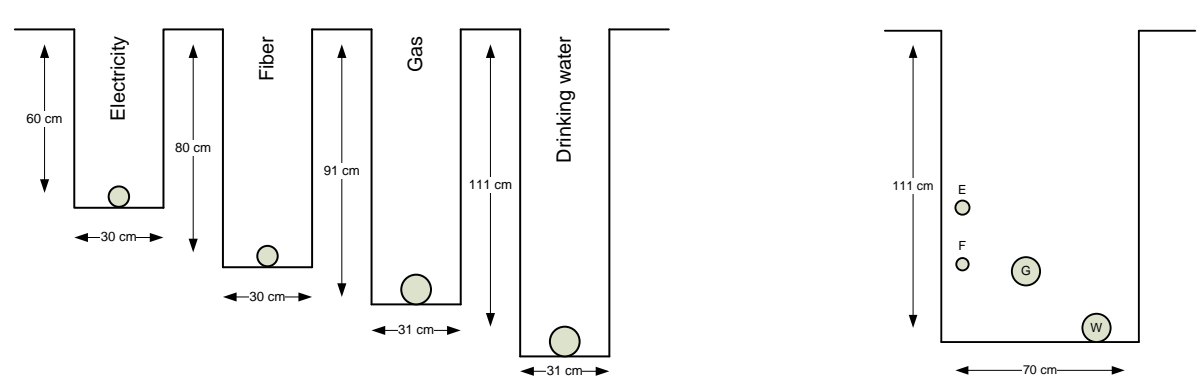

Figure 1: Joint trench optimization can drastically reduce both trench volume and affected pavement area, as shown by the trench cross-sections for stand-alone (left) versus joint greenfield rollout (right)

\section{PRAGMATIC SYNERgIES BASED ON GEOGRAPHIC PROXIMITY AND RELATED DEPLOYMENT TIME}

Clearly synergies can save a lot in the trenching costs and should be strived for. Still the infrastructure owners only consult each other on a relatively short term of their next installations, while the fixed planning and budgets of other infrastructure owners do not easily allow changing plans on this short term, hence complicate cooperating in this potential synergy. [7] presents a heuristic algorithm for aligning the planned road works of two (or more) infrastructure owners with the aim to increase the potential synergies by smart rescheduling of the planned road works.

This approach looks for overlapping and/or adjacent road works and tries to schedule them at the same time. The scheduling takes as input the geographical information of various scheduled projects from the different infrastructure providers and metadata linked to these projects from which e.g. the timing constraints, urgency, priority and maximum budget can be deduced. A heuristic scheduling algorithm uses this information with an aim to optimally plan the (initially unrelated) single-infrastructure projects into cooperative projects (Figure 2). This scheduling has both a view on network (overlapping in location) as on timing (overlapping in execution time) level. Again multiple objectives, such as the total cost, overall nuisance to the inhabitants, regional spread, etc. can be considered. This can further be extended to include e.g. also the logical scheduling of zones, so that optimal accessibility through the city can be assured. 
Rescheduling is performed within the constraints of a maximal yearly budget and a maximal time shift of each individual road work. The outcome of the rescheduling shows that potential synergies can be increased from $4 \%$ where road works are initially planned accidentally at the same time up to $25 \%$ in the optimal planning, based on a use case for a Flemish city [7].
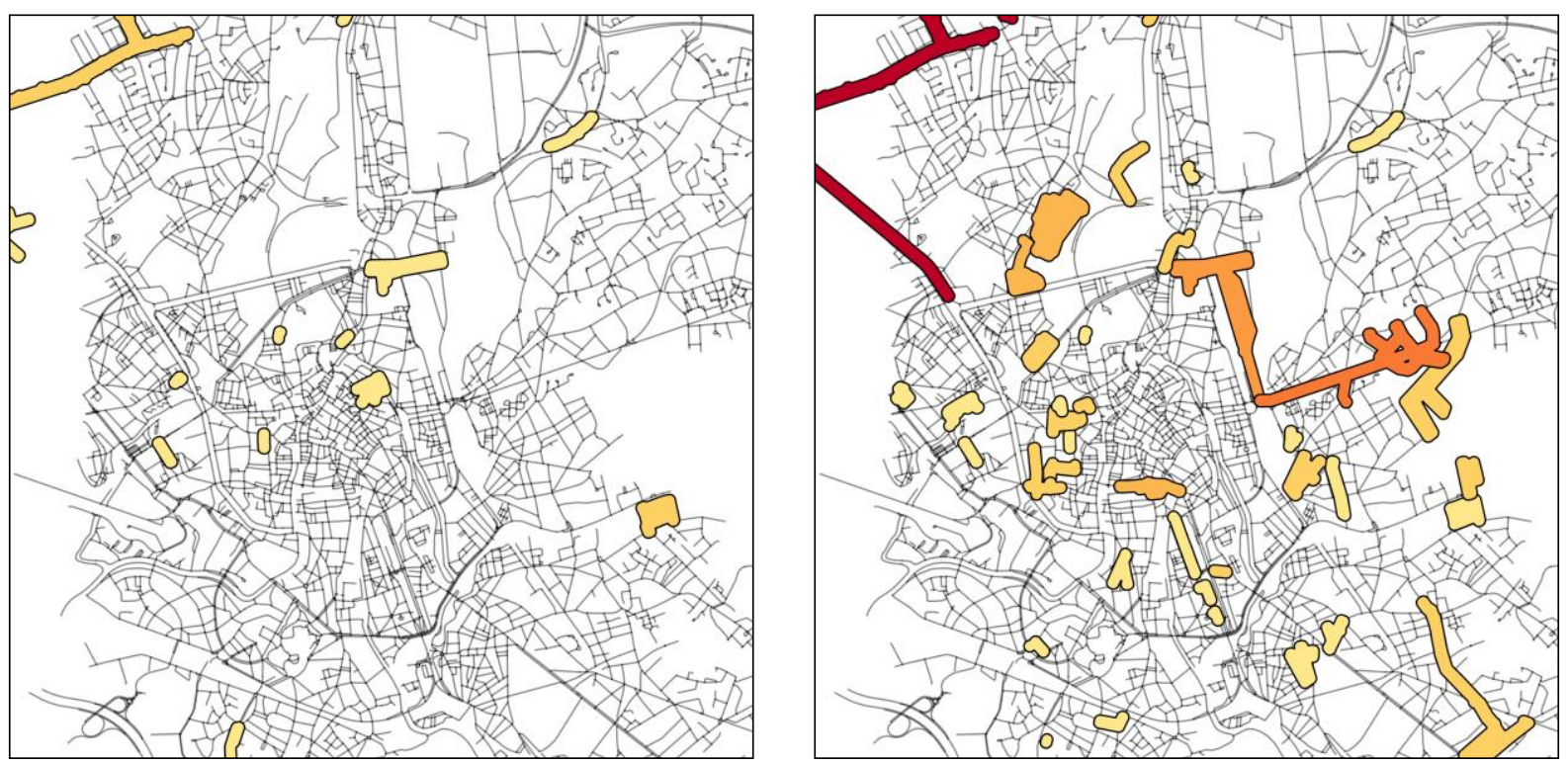

Figure 2: Optimized clustering based on geographic proximity and related deployment time has a significant impact on the amount of civil works that can be done in synergy,

as shown by the difference in the amount of clustered areas and in the colour (the darker the more works within the cluster) between the initial situation (left) and the result of the optimization algorithm (right)

\section{STRATEGIC SYNERGIES BASED ON LOCATIONS OF PUBLIC BUILDINGS}

If a city aims at strategic synergies by initially connecting its own public buildings, such as governmental offices and city services and in extension hospitals, schools, museums and other public care or recreational centers, it could already open up some of the advantages of an FTTH network to its citizens. One step further, the city could take a more foresighted deployment scenario into account, in which more ducts and feeders are deployed and some detours are allowed, to enable a faster and cheaper rollout towards businesses and/or residential customers afterwards. This approach is similar to the approach of Google Fiber in the US: by relying on public bodies to support the demand aggregation in their areas, they prioritize the actual rollout based on the results of this demand aggregation.

In [8], three rollout scenarios with varying focus and amount of foresight have been studied: joint, semi-joint and fully separate topology optimization for connecting public, business and residential buildings (Figure 3). Note that the actual deployment can still be done in a phased manner, independent on the way the topology planning is done. Note also that the fully separate topology optimization scenario serves as base case in which minimal reuse of planning and infrastructure is possible.

The results of this study show that the overall cost in the first and the second scenario can be significantly lower for connecting all public buildings as several routes can be shared and others dismissed based on the final optimal topology. Additionally, many overhead costs in planning and connecting in the later stages can be decreased, compared to the last scenario. In both first and second scenario, the infrastructure rolled out by the municipality can be seen as an open access network and can be used by each network and service provider in the area. As such, this constellation is not expected to cause any problems with EU competition law regulation as the initial network is built for the cities' own purpose. 


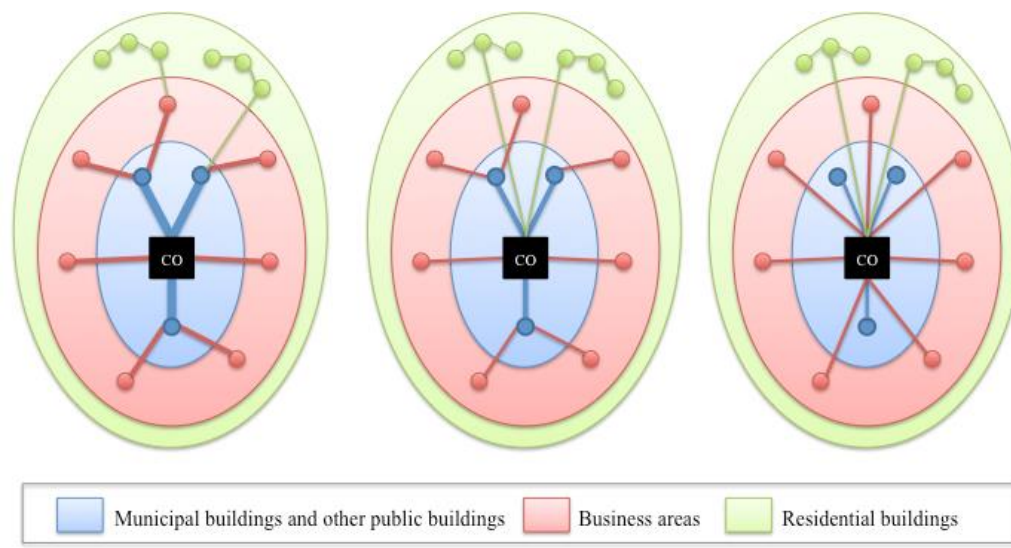

Figure 3: Rollout scenarios with joint (left), semi-joint (middle) and fully separate (right) topology optimization for public, business and residential buildings can lead to significantly different deployment costs

A phased rollout in which the city initiates (e.g. by means of tendering) the rollout of a public services fiber network could really improve the FTTH business case. Depending on the focus of the city, a business or fully residential FTTH network deployment could be stimulated by taking into account an optimal citywide topology planning approach early in the process. In addition cherry-picking should then be used to select the most optimal areas focusing on connecting first municipal and other public buildings.

\section{RECOMMENDATIONS}

There are two observations to be made concerning new broadband deployment in Europe. First and foremost, important economic as well as social benefits are attributed to broadband and especially Fiber-to-the-Home (FTTH) networks. For this reason, dedicated targets for broadband coverage and uptake are set, e.g. by the Digital Agenda for Europe. Secondly, in large parts of urban Europe, underground infrastructures are prevalent for conveying gas, water, electricity or telecom signals. As trenching comprises $70-80 \%$ of deployment cost, cost reductions in this cost category can have a major impact in reducing the high upfront investments for new infrastructures. Synergies in the deployment phase that directly impact the rollout cost are the focus of this paper. We have described three approaches towards synergetic rollout. First, we indicated that joint trench optimization amongst different utility providers (still taking into account safety measures and other legal constraints) can drastically reduce both trench volume and affected pavement area and therefore the cost of this trench. Second, we developed a pragmatic clustering optimization based on geographic proximity and related deployment time. Finally, a strategic approach towards rollout scenarios for public, business and residential buildings can lead to significant different deployment costs based on joint, semi-joint and fully separate topology optimization.

For future FTTH deployment (greenfield as well as brownfield) a thorough analysis needs to be done on all potential synergies to be found for the deployment phase, ranging from strategic synergies based on the order in which to connected different types of customers (public buildings, business, residential users) and the optimal trench layout to pragmatic synergies based on actual rollout plans (including locations and timings) from different utility providers.

\section{REFERENCES}

[1] Van der Wee, M., Verbrugge, S., Sadowski, B., Driesse, M. and Pickavet, M. (2015) Identifying and quantifying the indirect benefits of broadband networks for e-Government and e-Business: A bottom-up approach. Telecommunications Policy, 39(3-4), 176-191.

[2] Katz, R.L. and Vaterlaus, S. (2009) The impact of broadband on jobs and the German economy. Intereconomics, 45(1).

[3] Hayes, R. (2011) Valuing Broadband Benefits: A selective report on issues and options. Melbourne Business School, University of Melbourne.

[4] Forzati, M., Mattsson, C. and Al-E-Raza, S. (2012) Early effects of FTTH/FTTx on employment and population evolution. An analysis of the 2007-2010 period in Sweden. Conference of Telecommunication, Media and Internet Techno-Economics (CTTE, June 2012, Athens, Greece.

[5] 2014/61/EU Directive on reducing the cost of deploying high-speed electronic communications networks, May 2014, http://eur-lex.europa.eu/legal-content/EN/TXT/?uri=celex:32014L0061

[6] Tahon M., Van Ooteghem J., Casier K., Verbrugge S., Colle D., Pickavet M., Demeester P. (2011) Improving the FTTH business case - a joint telco-utility network rollout mode, Telecommunications Policy.

[7] Spruytte J., Tahon M., Casier K., Verbrugge S., Colle D., Pickavet M. (2014) Optimized synergy in networked infrastructure deployment and maintenance, ITS Europe.

[8] Van Ooteghem J., Casier K., De Heyn L., Meersman R., Rosseau B., Colle D., Pickavet M. (2012) Municipal driven fiber access network rollout, 19th ITS Biennial Conference, 18-21 November 2012, Bangkok, Thailand 